\title{
Kemampuan Argumentasi Pada Pembelajaran Biologi
}

\author{
Gita Karlina $^{1^{*}}$, Heffi Alberida ${ }^{2}$ iD \\ 1,2 Jurusan Biologi, Universitas Negeri Padang, Sumatera Barat, Indonesia \\ *Corresponding author: gitakarlina55@gmail.com
}

\begin{abstract}
Abstrak
Pandemi covid 19 saat ini berdampak pada berbagai sektor kehidupan terutama pendidikan. Setelah dilakukan observasi dan wawancara di SMA Adabiah Padang ditemukan permasalah sebagai berikut. Pertama, pandemi covid-19 mengakibatkan menurunnya kualitas keterampilan peserta didik. Kedua, peserta didik belajar pengetahuan namun kurang dituntut untuk mengaplikasikan dan menalar dalam menggunakan pengetahuan yang diperoleh dalam belajar. Ketiga, guru belum maksimal dalam melatihkan peserta didik dalam mengembangkan kemampuan argumentasi yang dimilikinya. Penelitian ini bertujuan untuk mendeskripsikan kemampuan argumentasi peserta didik kelas X MIPA SMA. Jenis penelitian ini adalah kuantitatif dengan metode deskriptif. Metode pengumpulan data menggunakan metode tes. Teknik penganalisisan data yang digunakan adalah dengan cara menganalisis data dari subjek penelitian yaitu peserta didik kelas X MIPA 4 dan X MIPA 5 SMA. Hasil penelitian ini diperoleh gambaran rata-rata kemampuan argumentasi peserta didik X SMA Adabiah Padang. Nilai rata-rata kelas X MIPA 4 yaitu 57,85\% dan X MIPA 5 yaitu 49\% rata-rata yang diperoleh oleh peserta didik adalah cukup dimana argumentasi terdiri dari argument-argument dengan rangkaian claim atau counter claim yang disertai dengan data, jaminan, atau dukungan dan sesekali sanggahan yang lemah (weak rebuttal).
\end{abstract}

Kata kunci: Kemampuan Argumentasi, Pembelajaran Biologi

\section{Abstract}

The current COVID-19 pandemic has had an impact on various sectors of life, especially education. After conducting observations and interviews at Adabiah Padang High School, the following problems were found. First, the COVID-19 pandemic has resulted in a decline in the quality of student skills. Second, students learn knowledge but are less required to apply and reason in using the knowledge gained in learning. Third, the teacher has not been maximal in training students in developing their argumentation skills. This study aims to describe the argumentation ability of students in class X MIPA SMA. This type of research is quantitative with descriptive method. Methods of data collection using the test method. The data analysis technique used is by analyzing data from the research subject, namely students of class X MIPA 4 and X MIPA 5 SMA. The results of this study obtained an overview of the average argumentation ability of students at SMA Adabiah Padang. The average grade X MIPA 4 is $57.85 \%$ and X MIPA 5 is $49 \%$ the average obtained by students is sufficient where the arguments consist of arguments with a series of claims or counter claims accompanied by data, guarantees, or support and occasional weak rebuttal.

Keywords: Argument Toulmin Pattern, The Learning Process

$\begin{array}{ll}\text { History: } & \\ \text { Received } & : \text { 29 Januari } 2021 \\ \text { Revised } & : 13 \text { Februari } 2021 \\ \text { Accepted } & : 1 \text { Maret } 2021 \\ \text { Published } & : 25 \text { Maret } 2021\end{array}$

Publisher: Undiksha Press

Licensed: This work is licensed under a Creative Commons Attribution 4.0 License

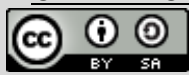

\section{Pendahuluan}

Pendidikan merupakan usaha sadar dalam membina dan mengembangkan kemampuan manusia secara utuh dan menyeluruh dengan menarik, menyenangkan dan menggembirakan. Pendidikan merupakan upaya perkembangan semua aspek kognitif, efektif, pisikomotorik maupun fisik. Pendidikan harus tetap diupayakan dan dilakukan perbaikan (Maulana, 2021). Salah satu cara untuk mencapai tujuan dari pendidikan adalah menciptakan suasana belajar yang mudah dan menyenangkan bagi perserta didik sehingga tujuan dari pembelajaran dapat tercapai (Widiyono \& Irfana, 2021). Pembelajaran biologi menjadi salah 
satu pembelajaran yang dapat mengembangkan berbagai kemampuan siswa (Sulastri \& Rochintaniawati, 2009). Pembelajaran biologi bertujuan untuk mengembangkan dan meningkatkan sebuah ilmu pengetahuan. Pendidikan menjadi fokus utama dalam upaya menjamin kualitas peserta didik yang memiliki kecakapan dan keterampilan dalam proses belajar, berinovasi, menggunakan teknologi, memilih media informasi, berfikir secara tepat, dan menentukan sumber informasi yang sesuai (Maulana, 2021). Dalam mempublikasikan ilmu pengetahuan melibatkan kritik dan argument (Hendri, 2015). Belajar melalui argumentasi akan melatih siswa untuk berpikir kritis mengevaluasi bukti atau saran dan mengambil keputusan. Dengan kata lain, argumentasi memegang peran penting pada pembelajaran biologi (Wahdan et al., 2017). Oleh karena itu, tujuan pembelajaran biologi seharusnya tidak lagi hanya untuk memahirkan konsep biologi namun juga belajar bagaimana melibatkan argumentasi dalam pembelajan biologi

Kenyaataan dilapangan, peserta didik pada proses pembelajaran hanya focus pada aspek pengetahuan namun kurang dituntut mengaplikasi dan menalar dan menggunakan pengetahuan yang diperolehnya dari proses belajar. Pembelajaran disekolah guru jarang mengajak peserta didik melakukan penalaran dan mengasah kemampuan berargumentasinya. Berdasarkan hasil observasi yang dilakukan pada tanggal 14 September 2020 di SMA Adabiah Padang menunjukkan bahwa guru masih menggunakan metode ceramah serta resitasi (penugasan) yang bersifat Teacher Centered efek jangka panjang dari pembelajaran daring yang dilakukan saat ini. Kemampuan argumentasi peserta didik kelas X SMA Adabiah Padang masih rendah. Efek jangka panjang pemindahan pengetahuan dari guru ke peserta didik tidak dapat mengembangkan kemampuan yang dimiliki melalui pengalaman yang diperolehnya dalam berbagai konten pengetahuan dan pembelajaran disekolah.

Kemampuan argumentasi membantu siswa untuk mengembangkan kemampuan metakognisi dan berfikir tingkat tinggi, karena argumentasi mendorong setiap individu untuk mengeksternalisasi dan merefleksi hasil penalaran/pemikiran sendiri (Haruna, 2021). Argumentasi menjadi objek dari kegiatan dan dapat didefinisikan sebagai keterampilan yang seharusnya dimiliki oleh siswa untuk mendukung, membuat hubungan antara fakta dan konsep, serta untuk mentransfer pencapaian pengetahuan ke dalam contoh kehidupan seharihari (Erduran \& Simon,2018). Selain itu, kemampuan argumentasi merupakan fondasi dari berpikir logis dan kritis. Argumentasi secara dasar memiliki tiga penggunaan, yaitu argumen sebagai kontroversi antara dua posisi, argumen sebagai perdebatan, dan argumen sebagai pembenaran (Rahman et al., 2018). Argumen sebagai pembenaran diperlukan setidaknya satu alasan dan kesimpulan. Ciri argumentasi salah satunya melibatkan pertentangan untuk mendukung klaim, melibatkan konflik, keraguan, ketidaksetujuan (Baumtrog, 2018).

Beberapa temuan penelitian terdahulu terkait analisis kemampuan argumrntasi menyatakan kemampuan argumentasi ilmiah sangat penting dalam mempersiapkan siswa yang berliterasi sains (Rahman et al., 2018). Faktor-faktor yang mempengaruhi kemampuan berargumentasi ilmiah peserta didik adalah pemahaman peserta didik terhadap materi ikatan kimia dan keterlibatan peserta didik dalam kegiatan argumentasi selama proses pembelajaran (Wahdan et al., 2017). Kemampuan argumentasi ilmiah tertulis siswa melalui model pembelajaran Inkuiri Terbimbing dengan Inkuiri Terbimbing dipadu Dialog Socrates dapat meningkat (Wahdan et al., 2017).

Kemampuan argumentasi ilmiah sangat penting untuk dilatihkan didalam pembelajaran agar peserta didik memiliki nalar yang logis, pandangan yang jelas, dan penjelasan yang rasional dari hal-hal yang dipelajari. Selain itu kemampuan argumentasi dapat membekali peserta didik untuk memberikan penjelasan tehadap fenomena yang terjadi dalam kehidupan sehari-hari berdasarkan teori/konsep IPA. Argumentasi akan mendorong peserta didik untuk terlibat dalam memberikan bukti, data, serta teori yang valid untuk mendukung pendapat (klaim) terhadap suatu permasalahan (Robertshaw, \& Campbell, 2013). 
Oleh sebab itu kemampuan argumentasi perlu dilatihkan melalui pembelajaran. Berdasarkan uraian masalah diatas, penulis melakukan penelitian mengenai kemampuan argumentasi pada pembelajaran biologi di SMA Adabiah Padang.

\section{Metode}

Jenis penelitian ini ialah penelitian kuantitatif dengan menggunakan metode deskriptif. Subjek penelitian ini adalah siswa kelas X MIPA 4 dan X MIPA 5 SMA Adabiah Padang. Jumlah peserta didik sebanyak 34 orang siswa. Penelirian ini dilaksanakan di SMA Adabiah Padang. Instrument penelitian ini adalah soal esai sebanyak 6 butir untuk mengetahui kemampuan argumentasi peserta didik kelas X MIPA 4 dan X MIPA 5 di SMA Adabiah Padang. Pengumpulan data dalam penelitian ini dilaksanakan dengan memberikan tes kemampuan argumentasi. Tes dilakukan sebanyak satu kali. Untuk menentukan skor kemampuan argumentasi peserta didik dilihat dari 5 indikator yaitu berupa claim (klaim), data (data), warrant (pembenaran), backing (dukungan), dan warrant (sanggahan) pada setiap indikator memiliki skor masing-masing, yaitu skor terendah 1 dan skor tertinggi 5 . Teknik penganalisisan data yang digunakan dalam penelitian ini adalah dengan cara menganalisis data dari subjek penelitian yaitu peserta didik kelas X MIPA 4 dan X MIPA 5 SMA Adabiah Padang. Data yang terkumpul melalui langkah-langkah sebagai berikut. Pertama, memeriksa hasil kemampuan argumentasi peserta didik. Kedua, memberi skor hasil kemampuan argumentasi yang telah dikerjakan oleh peserta didik dengan cara memberi skor 1 untuk terendah dan skor 5 untuk tertinggi.

Argumentasi yang diguankan dalam penelitian ini terdiri dari argumen berupa claim sederhana dengan claim berlawanan (counter claim) dengan skor 1, argumentasi terdiri dari argument-argumen berupa claim dengan counter claim disertai data, jaminan (warrant), atau dukungan (backing) tetapi tidak mengandung sanggahan (rebuttal) dengan skor 2, argumentasi terdiri dari argument-argument dengan rangkaian claim atau counter claim yang disertai dengan data, jaminan, atau dukungan dan sesekali sanggahan yang lemah (weak rebuttal) diberi skor 3, argumentasi terdiri dari argument-argumen dengan claim dengan satu sanggahan yang dapat diidentifikasi jelas dan tepat, satu argumen dapat mengandung claim atau counter claim diberi skor 4, sedangkan jika argumentasi terdiri dari argument-argumen yang luas, namun terkait dengan materi pelajaran) dengan lebih dari satu sanggahan yang jelas dan tepat diberi skor 5 .

Tabel 1. Level Indikator Kemampuan Argumentasi

\begin{tabular}{clc}
\hline Indikator & \multicolumn{1}{c}{ Kriteria } & Nilai \\
\hline \multirow{2}{*}{ Claim } & $\begin{array}{l}\text { Argumentasi terdiri dari argument-argumen berupa claim sederhana } \\
\text { dengan claim berlawanan (counter claim) }\end{array}$ & 1 \\
Data & $\begin{array}{l}\text { Argumentasi terdiri dari argument-argumen berupa claim dengan } \\
\text { counter claim yang disertai data, jaminan (warrant) atau dukungan } \\
\text { (backing) tapi tidak mengandung sanggahan (rebuttal) }\end{array}$ & 2 \\
Warrant & $\begin{array}{l}\text { Argumentasi terdiri dari argument-argumen dengan rangkaian claim } \\
\text { atau counter claim yang disertai dengan data, jaminan atau dukungan } \\
\text { dengan sesekali sanggahan yang lemah. }\end{array}$ & 3 \\
Backing & $\begin{array}{l}\text { Argumentasi terdiri dari argument-argumen dengan claim dengan satu } \\
\text { sanggahan yang dapat diidentifikasi jelas dan tepat, satu argument } \\
\text { dapat mengandung beberapa claim atau counter claim. }\end{array}$ & 4 \\
Argumentasi terdiri dari argument-argumen yang luas (extended, \\
Rebuttal \\
namun tetap terkait dengan materi pembelajaran) dengan lebih dari \\
satu sanggahan yang jelas.
\end{tabular}

Tabel 2. Pedoman Interpretasi Penilaian 


\begin{tabular}{ccc}
\hline Interpretasi Skor & Level Skor & Kualifikasi \\
\hline $0 \%-19 \%$ & 1 & Sangat Lemah \\
$20 \%-39 \%$ & 2 & Lemah \\
$40 \%-59 \%$ & 3 & Cukup \\
$60 \%-79 \%$ & 4 & Kuat \\
$80 \%-100 \%$ & 5 & Sangat kuat \\
\hline
\end{tabular}

\section{Hasil dan Pembahasan}

Tahap penelitian dilakukan satu kali pertemuan, dengan melakukan uji tes kemampuan argumentasi peserta didik dengan menggunakan soal esai kepada peserta didik kelas X SMA Adabiah Padang. Penelitian yang dilakukan di SMA Adabiah Padang bertujuan untuk mengetahui kemampuan argumentasi peserta didik kelas X. kemampuan argumentasi diukur secara tulisan berupa soal esai. Esai yang diberikan berjumlah 6 butir soal dengan 5 indikator kemampuan argumentasi. Indikator tersebut memiliki skor terendah yaitu 1 dan skor tertinggi yaitu 5 .

Tabel 3. Kategori Kemampuan Argumentasi Peserta Didik X MIPA 4

\begin{tabular}{cccc}
\hline Klasifikasi Nilai & Kualifikasi & X MIPA 4 (\%) & X MIPA 5 (\%) \\
\hline $0 \%-19 \%$ & Sangat Lemah & 2,9 & 0 \\
$20 \%-39 \%$ & Lemah & 5,8 & 11,76 \\
$40 \%-59 \%$ & Cukup & 50 & 44,11 \\
$60 \%-79 \%$ & Kuat & 29,41 & 20,58 \\
$80 \%-100 \%$ & Sangat Kuat & 11,76 & 0 \\
\hline \multicolumn{2}{c}{ Rata-Rata } & $\mathbf{5 7 , 8 5}$ & $\mathbf{4 9}$ \\
\hline
\end{tabular}

Tabel 3 menunjukkan bahwa rata-rata nilai tertinggi diperoleh oleh kelas X MIPA 4. Nilai ini diambil dari perhitungan kuantitatif dengan menghitung adanya unsur pada setiap jawaban oleh responden. Dengan memperhatikan jawaban dari responden kemudian dianalisis berdasarkan ada tidaknya unsur argumentasi pada setiap jawaban. Hasil menunjukkan bahwa kelas X MIPA 4 mendapatkan rata-rata 57,85\% dan kelas X MIPA 5 mendapatkan rata-rata $49 \%$, yang artinya peserta didik memiliki kemampuan argumentasi cukup kuat. Hasil dari penjumlahan ada atau tidaknya komponen tersebut dapat digambarkan dengan Gambar 1. Berdasarkan hasil analisis data maka dari penelitian ini diperoleh gambaran kemampuan argumentasi peserta didik kelas X MIPA 4 dan X MIPA 5 SMA Adabiah Padang berdasarkan indikator kemampuan argumentasi dapat terlihat bahwa peserta didik dalam menjawab soal sudah mampu mengemukakan kemampuan argumentasi yang dimilikinya untuk indikator claim 14,7 kelas X MIPA 4 mengemukakan claim pada setiap soal sedangkan untuk kelas X MIPA 5 yaitu 11,76 dimana nilai yang diperoleh berada pada indikator 1 dimana argumentasi terdiri dari argument berupa claim sederhana dengan claim berlawanan (counter claim). Untuk indikator data MIPA 4 yaitu 76.47 sedangkan MIPA 5 yaitu 52,94 peserta didik memiliki argumentasi terdiri dari argument-argumen berupa claim dengan counter claim disertai data, jaminan (warrant), atau dukungan (backing) tetapi tidak mengandung sanggahan (rebuttal). 


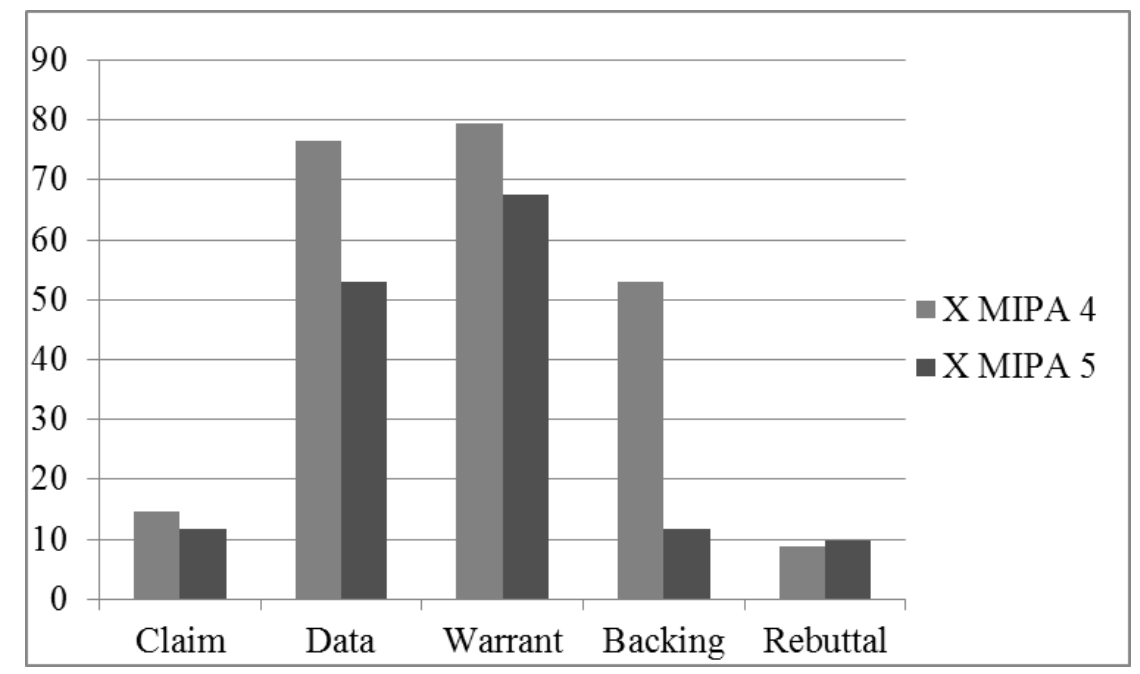

Gambar 1. Indikator Kemampuan Argumentasi Peserta Didik

Jumlah unsur Warrant MIPA 4 yaitu 79,41 dan MIPA 5 yaitu 67,64 argumentasi terdiri dari argument-argument dengan rangkaian claim atau counter claim yang disertai dengan data, jaminan, atau dukungan dan sesekali sanggahan yang lemah (weak rebuttal. Jumlah indikator backing MIPA 4 yaitu 52,94 dan MIPA 5 yaitu 11,76 dimana argumentasi terdiri dari argument-argumen dengan claim dengan satu sanggahan yang dapat diidentifikasi jelas dan tepat, satu argumen dapat mengandung claim atau counter claim. Yang terakhir yaitu indikator rebuttal MIPA 4 yaitu 8,82 sedangkan MIPA 5 yaitu 9.82 dimana argumentasi terdiri dari argument-argumen yang luas, namun terkait dengan materi pelajaran dengan lebih dari satu sanggahan yang jelas dan tepat. Sebagian besar peserta didik memiliki kemampuan argumentasi yang mampu menyertakan data dan konsep yang kokoh namun peserta didik hanya menyampaikan pendapat tanpa adanya dukungan yang konkrit dari pendapat yang dituliskan. Dan apabila peserta didik menyampaikan data, data tersebut kurang akurat dan peserta didik terbiasa mencari sumber pustaka non ilmiah yang tidak terpercaya.

Kemampuan argumentasi peserta didik pada seluruh aspek secara umum memiliki kemampuan argumentasi yang cukup (Toharudin, 2020). Hal ini terbukti dari rata-rata hasil tes yait. Secara keseluruhan peserta didik memiliki kemampuan argumentasi yang perlu diasah lagi agar kemampuan argumentasi yang dimiliki oleh peserta didik dapat menjawab segala tantangan zaman karena kemampuan argumentasi ilmiah sangat penting untuk dilatihkan didalam pembelajaran agar peserta didik memiliki nalar yang logis, pandangan yang jelas, dan penjelasan yang rasional dari hal-hal yang dipelajari (Diniya et al., 2021; Gunawan et al., 2021). Selain itu kemampuan argumentasi dapat membekali peserta didik untuk memberikan penjelasan tehadap fenomena yang terjadi dalam kehidupan sehari-hari berdasarkan teori/konsep IPA.

Kemampuan argumentasi sangat penting bagi peserta didik karena kemampuan argumentasi menjadi salah satu tujuan pembelajaran sains karena peserta didik belajar mengetahui penjelasan ilmiah mengenai fenomena alam dan menggunakan argumentasi untuk memecahkan masalah sehingga mengetahui sains secara utuh. Keterampilan argumentasi sangat penting untuk dilatihkan dalam pembelajaran sehingga peserta didik memiliki nalar yang logis, pandangan yang jelas dan penjelasan yang rasional dari hal-hal yang dipelajari. Kegiatan pembelajaran berbasis argumentasi dapat mendorong peserta didik untuk terlibat dalam memberikan bukti, data, dan teori yang valid untuk mendukung pendapat terhadap suatu permasalahan. 
Beberapa temuan penelitian terdahulu terkait analisis kemampuan argumrntasi menyatakan kemampuan argumentasi ilmiah sangat penting dalam mempersiapkan siswa yang berliterasi sains (Rahman et al., 2018). Faktor-faktor yang mempengaruhi kemampuan berargumentasi ilmiah peserta didik adalah pemahaman peserta didik terhadap materi ikatan kimia dan keterlibatan peserta didik dalam kegiatan argumentasi selama proses pembelajaran (Wahdan et al., 2017). Secara umum, kemampuan argumentasi dari penelitian ini menunjukan kemampuan argumentasi sudah baik, namun penelitian ini hanya memfokuskan pada pembelajaran biologi. Selain itu sampel yang digunakan berjumlah 34 siswa, sehingga diharapkan penelitian selanjutnya dapat menggunakan sampel yang lebih banyak sehingga hasil yang diperoleh lebih optimal.

\section{Simpulan}

Berdasarkan hasil penelitian dapat disimpulkan bahwa kemampuan argumentasi peserta didik cukup kuat. Namun, beberapa kemampuan argumentasi peserta didik masih tergolong kurang baik, hal tersebut disebabkan oleh kualitas argumentasi yang sebagian besar hanya berisi claim dengan adanya data yang kurang akurat yang melandasi claim tersebut atau bahkan belum mampu menyertakan dukungan dari pendapat yang disampaikan. Peserta didik hendaknya mampu mengasah kemampuan argumentasi yang dimilikinya agar peserta didik memiliki nalar yang logis, pandangan yang jelas, dan penjelasan yang rasional terhadap hal-hal yang dipelajari. Kepada guru SMA Adabiah Padang, khususnya guru biologi diharapkan dapat memberikan tindakan yang praktis berupa memberikan latihan-latihan atau soal-soal yang dapat memotivasi peserta didik dalam mengembangkan kemampuan argumentasi yang dimilikinya.

\section{Daftar Rujukan}

Diniya, D., Ilhami, A., Mahartika, I., Permana P, N. D., \& Prakash, O. (2021). Kemampuan Argumentasi Ilmiah Calon Guru IPA melalui Pendekatan MIKiR selama Pandemi Covid-19. Journal of Natural Science and Integration, 4(1), 141. https://doi.org/10.24014/jnsi.v4i1.12770.

Erduran, S., \& Simon, S., \& Osborne, J. (2018). TAPping into argumentation: Developments in the application of Toulmin's Argument Pattern for studying science discourse. Science Education, 88(6), 915-933. https://doi.org/10.1002/sce.20012.

Gunawan, Purwoko, A. A., Ramdani, A., \& Yustiqvar, M. (2021). Pembelajaran Menggunakan Learning Management Systemberbasis Moodle pada Masa Pandemi Covid-19. Indonesian Journal of Teacher Education, 2(1), 6. https://journal.publication-center.com/index.php/ijte/article/view/696/160.

Haruna, A. (2021). Menjelajahi Hubungan Level Argumentasi Dengan Kemampuan Berfikir Kritis Siswa Dalam Menyelesaikan Soal Ikatan Kimia. Jurnal Inovasi Pendidikan Kimia, 15(1),

2686-2694. https://journal.unnes.ac.id/nju/index.php/JIPK/article/view/24156.

Hendri, S. (2015). Review : Membentuk Keterampilan Argumentasi Siswa Melalui Isu Sosial Ilmiah dalam Pembelajaran Sains. Inovasi Dan Pembelajaran Sains, 2015(Snips), $545-548$.

Maulana, M. A. (2021). Efektivitas Pembelajaran Daring Terhadap Hasil Belajar Biologi Pada Konsep Biodiversitas Di Kelas X Ipa Ma Muhammadiyah Salaka Kabupaten Takalar. Jurnal Riset Dan Inovasi Pembelajaran, 1(1), 85-95. https://doi.org/10.51574/jrip.v1i1.22.

Rahman, A., Diantoro, M., \& Yuliati, L. (2018). Kemampuan Argumentasi Ilmiah Siswa pada Hukum Newton di Sek.olah Menengah Atas. Jurnal Pendidikan: Teori, 
Penelitian, \& Pengembangan, 903-911. https://doi.org/10.17977/jptpp.v3i7.11337.

Robertshaw, B, \& Campbell, T. (2013). Constructing Arguments: Investigating Pra-Service Science Teacher's Argumentation Skills In A Socio Scientifik Context. Science Education International Journal, 24(1), 195-211. https://eric.ed.gov/?id=EJ1015818.

Sulastri, Y., \& Rochintaniawati, D. (2009). Pengaruh Penggunaan Pembelajaran Kooperatif Tipe Jigsaw Dalam Pembelajaran Biologi Di Smpn 2 Cimalaka. Jurnal Pengajaran Matematika Dan Ilmu Pengetahuan Alam, 13(1), 15. https://doi.org/10.18269/jpmipa.v13i1.302.

Toharudin, U. (2020). Implementasi Model Inkuiri Terbimbing Berbasis Lesson Study dalam Menumbuhkan Kemampuan Argumentasi Komunikasi dan Kognitif Mahasiswa. Bioedusains: Jurnal Pendidikan Biologi Dan Sains, 3(2), 1689-1699. https://journal.ipm2kpe.or.id/index.php/BIOEDUSAINS/article/view/1762.

Wahdan, W. Z., Sulistina, O., \& Sukarianingsih, D. (2017). Analisis Kemampuan Berargumentasi Ilmiah Materi Ikatan Kimia Peserta Didik Sma, Man, Dan Perguruan Tinggi Tingkat I. J-PEK (Jurnal Pembelajaran Kimia), 2(2), 30-40. https://doi.org/10.17977/um026v2i22017p030.

Widiyono, A., \& Irfana, S. (2021). Implementasi Merdeka Belajar melalui Kampus Mengajar Perintis di Sekolah Dasar. Metodik Didaktik: Jurnal Pendidikan Ke-SD-An, 16(2), 102-107. https://doi.org/10.17509/md.v16i2.30125. 